\title{
LOS JORNALEROS
}

Sandra Barba*

A Julián, en respuesta a su famélico.

\section{Los demasiados días}

Qu'ils meurent pleins de jours

06:35:03

Dormí de más. De nuevo falto a la promesa de levantarme de la cama con el primer pitido del despertador.

$06: 35: 26$

Mientras camino hacia la ducha hago mi habitual resta diurna. No sé cuándo empecé con la manía de cronometrar cada segundo del día, pero recuerdo que ayer me fui a la cama antes de las doce y que desperté a las seis con treinta y cinco (¡cinco gloriosos minutos más de sueño!), lo que significa que dormí casi siete horas; seis horas con cuarenta y dos minutos para ser preciso, y la precisión importa: me enfurece no dormir, al menos, ocho horas por noche. Y es que si la jornada laboral se define por un tercio del día, misma proporción debiera guardar la del descanso. Debo estar listo antes de las siete, pese a los cinco minutos que llevo de retraso, si quiero evitar la caravana vehicular matutina.

$06: 58: 57$

Apenas un minuto y tres segundos de ventaja le llevo a los que me acompañan en el camino diario a la oficina. Todos ellos trajeados y enla-

* Estudiante (Ciencia política, ITAM). 
tados en sedanes multicolores que, pese a contar con ciento veinticinco caballos de fuerza y una transmisión manual de seis velocidades, se dedican a entorpecer con su lenta marcha la vía pública. Debo sortear con destreza aquel estacionamiento itinerante y hacerme de los atajos que aprendí tras años de esforzado estudio de topografía urbana.

\section{7:59:00}

Justo a tiempo. Hago un brindis silencioso con una taza del azucarado café de maquinita mientras recorro el pasillo que me lleva al cubículo que tengo por oficina.

\section{$10: 45: 10$}

Es hora del primer cigarrillo del día. Del cajón derecho de mi escritorio, tomo los Marlboro rojos cajetilla dura-siempre he desconfiado de la blanda- y no puedo evitar leer, con mirada sardónica, la locución latina impresa en su blanca carátula: Veni, vidi, vici. Cuando lo cierto es que yo no soy ni jamás seré Julio César, ni me gobierna un senado al que pueda dirigirle una expresión tan soberbia. Yo vine, vi y fui vencido, como tanta otra carne de cañón de la población económicamente activa. Sin embargo, atiendo a las normas de salud redactadas por nuestro Honorable Congreso y enciendo mi primer cigarrillo fuera de este edificio cuya larga verticalidad es un homenaje a la modernidad iberoamericana. Estas bocanadas de humo me permiten derrochar al menos cinco minutos de la jornada en un ocio tóxico que, si bien no está explícitamente permitido, tampoco ha sido prohibido por la Honorable Cámara de Diputados en su cruzada contra el tabaco. Desde aquí puedo ver, en contra esquina, ese puesto de lámina dedicado a la gastronomía chatarra y me alivio de no contarme entre el batallón del subempleo, ni de engrosar las filas del desempleo que, por otro lado, siempre es una posibilidad amenazante. Ya han pasado cinco minutos y debo terminar la presentación del nuevo sedán que lanzaremos al mercado, ¿o, debería decir, a la embrutecida marcha sobre Periférico de la legión oficinista? 


\section{$13: 15: 59$}

Está lista. Salvo por el eslogan, que no me convence, parece estar lista. Aunque nunca sé qué querrá el que tengo por jefe. Y es que al legítimo dueño de mis horas podría antojársele cambiar los colores de la presentación para que combinen con los del carro prototipo, ¡como si semejante cosa importara!

Bien, aún queda un cuarto de hora y puedo darme la licencia de navegar por la Red; pasatiempo que ni la Honorable Cámara de Diputados ni el Honorable Consejo Administrativo de la compañía, en su manual de buenas prácticas, han prohibido. ¡Vaya, vaya! ¡Imagínese usted a qué cumbres han ascendido mis compañeros de la licenciatura! Miren, por ejemplo, a Carmela bañándose alegremente en no-sé-qué playa del Mediterráneo. Claro que toda la generación celebró su matrimonio con Juan Antonio; aunque ninguno de ellos fuera invitado a pasar un par de días en el yate de su flamante marido ni a navegar alegremente por un mar tan extenso y profundo como el de las piernas de Carmela. ¿Por qué fue que rechazaste mi invitación al Bellini? ¿Debería de haberte ofrecido más para que me invitaras a recorrer tu cuerpo? ¿Una cena en Au Pied de Cochon, tal vez? La verdad es que ni ayer ni hoy habría podido pagarlo, y ese fue el criterio para que me mandaras a volar, ¿o se te hizo kitsch embarcarte en la travesía aérea del único restaurante giratorio en México? Un mensaje de mi jefe interrumpe la representación fotográfica de tanta dicha ajena: la junta está por empezar.

\section{$15: 55: 37$}

Lo sabía. Debo cambiar la presentación para que el color empate con el del carro prototipo: Rojo Ignición o Rojo Burdeos o cualquier otra extravagancia del rojo que satisfaga los deseos de mi querido dictador. Una amable alarma me alivia de sus caprichos: he recibido un correo nuevo. Lo reviso y, ¡qué veo!, Carmela ha actualizado su perfil. Alguien, seguramente Juan Antonio, la ha fotografiado en una campiña francesa mientras disfruta de un Bordeaux tan rojo como el de mi sedán prototipo. ¡Basta! ¡Su exagerada promoción de la joie de vivre no me permite trabajar, ni siquiera en los "cambios mínimos" que me sugirió 
el patrón! Debo distraerme y pensar en el maldito eslogan, ahora mismo bajaré a comer.

\section{$16: 10: 06$}

Esta comida de cuatro tiempos me entristece tanto como el remedo de jardín que tengo enfrente: árboles enfundados en una lechosa pintura blanca y bordeados de miserables caminos polvorientos, y es que, indudablemente, "la delegación no tiene recursos para adoquinarlos". También tengo frente a mí esta insípida pasta, tan correosa como las bolsas de plástico que algún bribón colocó en los árboles del parque para enriquecer su follaje. Sentado a la mesa, enfundada también en un mantel de plástico, me pregunto qué tengo yo que ver con esa falsa joie de vivre que Carmela y el resto de mi generación promocionan en sus escaparates virtuales; cuando está claro que a mí nadie me invitó a surcar el Mediterráneo en yate ni a disfrutar de cualquier otra expresión del majestuoso banquete de la vida y, por esa misma razón, sería ridículo que me exigiesen cantarle al subdesarrollado parque que tengo por campo. Salut, champs que j’aimais! ¡Qué patraña! ¡Que nadie le cierre los ojos!

\section{$17: 41: 15$}

De nuevo, tomé más de una hora para comer y aún no he pensado en el eslogan de venta. Evito encontrarme con el patrón y hago mi habitual resta vespertina. Me repito que no recuerdo cuándo empecé a cronometrar cada segundo del día, pero la jornada expira en dieciocho minutos con cuarenta y cinco segundos y así, con el tiempo encima, es imposible pensar en cambios y slogans.

18:02:29

Me libro del patrón por el resto de la tarde. Lo celebro con bocinazos en la cotidiana marcha sobre el Periférico.

21:37:58

Rasgo el empaque de mi cena plastificada y le ensarto un tenedor desechable mientras me embrutezco frente al televisor. Si fuera capaz de 
desprenderme de él en menos de media hora, podría irme a la cama antes de las once y -jesta vez sí!- conquistar mi tercio de jornada nocturna.

$06: 35: 23$

\section{Los dichosos días}

Ahora mismo subiré a la Red las fotos que nos tomamos en Bordeaux. Es preciso que lo haga ahora mismo, antes de que pasen los días y lo olvide. La verdad es que la mayoría de ellas no están mal y, lo que es mejor, en muchas es casi imposible distinguir los surcos del tiempo que ya me amenazan por el rabillo del ojo; esas malditas trincheras y avanzadas de la vejez que todas las mañanas y todas las noches combato con lociones antiedad llenas de crema y de promesa. Sí, subiré ésta que tomó Juan Antonio como foto de perfil, ésta y no otra porque la mortecina luz del crepúsculo ayuda a enmascarar mi inexorable derrota frente a la vejez. ¡Pero cuánto han envejecido mis compañeros de universidad! Hoy no son más que miserables ventrudos aletargados, ¡y cómo no habrían de serlo si cada día deben cargar en el abdomen el sino del nuevo proletariado! Parece que, al menos en términos relativos, voy ganando la batalla contra el envejecimiento. Esa villanía del tiempo, esa maldita tiranía a la que... ipero qué veo! ¡Humberto está online!, aunque nunca estuvo in. Todavía recuerdo por qué rechacé su invitación al Bellini, y es que esa misma noche Juan Antonio me llevó a cenar al Pied de Cochon. La verdad es que Humberto siempre fue un mezquino: le enfurecía pagar los cinco mil pesos de renta de su miserable departamentito, allá por Avenida del Imán. Miserable, sí, siempre fuiste un miserable. "Tus años me hacen miserable, Carmela", todavía recuerdo la firmeza con la que Juan Antonio dictó la sentencia sexual de nuestro matrimonio, ése que mi generación de licenciatura celebró como el más afortunado y dichoso de los enlaces debido a las propiedades 
y, sobre todo, al yate de mi marido miserable. ¿Cómo iba a saber, Humberto, que en ese pueril día trocaría todas las promesas de mi vida por esta ordinaria medianía? ¿Cómo iba a saberlo?, increpo mientras el guiño del cursor me embrutece. Sin más, escribo:

Humberto, saludos desde Bordeaux.

Delete.

No, mejor no; no así, al menos. Es muy probable que Humberto haya terminado como los ventrudos licenciados de mi generación y, por otro lado, su mezquindad podría hacerle pensar que le estoy echando en cara el maldito vino tinto con el que posé, pero que no bebí, para mi foto de perfil. No, algo más amable, más cercano...

Querido Humberto...

Querido Humberto... ¿Querido Humberto?, sí:

Querido Humberto, cada día me aburro tanto como las ostras que me comí ese día en Au Pied de Cochon con Juan Antonio. ¡Pero qué digo!

Delete, delete, delete.

Delete all? Yes, delete all.

¡Ay Humberto! Si te escribo lo que siento, estoy segura de que pensarías: “Otra Madame Bovary”, peor aún: "Una envejecida Anna Karénina”, y la verdad es que yo no estoy ni jamás estaré tan desesperada como ellas, ni tendré frente a mí un affaire con un oficial tan gallardo como el Conde Vronsky. No, me repito que no soy tan miserable como ellas, ipero qué!, Humberto is no longer online, ipero si apenas pasaron quince minutos y ya se desconectó! ¡Ay Humberto!, ¿recuerdas cuando paseábamos juntos por los Viveros de Coyoacán?, ¿recuerdas cuánto reproché tu ineptitud para apreciar la belleza del mundo?, la belleza, sí, aunque expire y aunque la vejez y la muerte hayan ganado ya el terreno junto a mis ojos. Otro que ya viene es mi marido; antes de tomar una decisión, pregunto:

-Juan Antonio, ¿recuerdas a Humberto, de la universidad? -¿A quién? 
-Humberto Robles, de la licenciatura... ¡Y Ya! ¡Claro que lo recuerdas! Éramos todos amigos.

-Más amigo tuyo que mío, querida.

-Bueno, sí, ¿pero no te gustaría invitarlo a cenar cuando regresemos a México? Bien sabes que, desde que Marcela canceló, sobra un lugar en la mesa del comedor. Además, ¡nos ayudaría a recordar buenos tiempos!

- ¿Como los tiempos en los que te invitaba al Bellini?

-¡Eres un pesado! Sabes que jamás acepté su invitación. No, querido, serviría para que todos recordáramos buenos tiempos.

-Haz lo que te venga en gana.

-¿Entonces sí?

-Lo que te venga en gana, Carmela.

Sin más, escribo:

Humberto, nos gustaría saber cómo has estado y verte pronto. Salut!

Lo escribo así, aunque tenga cierto aire de saludo prefabricado.

Send.

Humberto is no longer on line and he will get your message when he is again connected.

Aun así: send.

\section{Los demasiados y dichosos días}

\section{$07: 53: 17$}

De nuevo llegué con tiempo a la oficina, de nuevo y pese a haberme tomado cinco minutos más de sueño. Cinco minutos, cinco, quince o tal vez veinte minutos que podré derrochar en la Red mientras llega mi jefe; los disfrutaré aunque siempre sea yo quien tiene que pagar la frustración que le provocan sus retrasos, yo quien... tiene un mensaje de Carmela. De la pantalla del ordenador, leo: You have a message from Carmela. You have a message from Carmela?

Humberto, nos gustaría saber cómo has estado y verte pronto. Salut! 
¡Qué estúpida! ¡Qué estúpida y qué fríos sus saludos! ¡Ay, Carmela, la aristocracia mexicana ha hecho de ti una más de sus falsas cortesanas! Otro país te habría convertido, tal vez, en una magnífica Anna Karénina, pero aquí, en el subdesarrollo y codeada de la oligarquía del subdesarro1lo, sólo podías llegar a triste Catalina después de que te arrancaran la vida. ¿Te aburres, Catalina, te aburres como las ostras que pescas en el yate de Juan Antonio? ¡Te aburres, desdichada! ¿Y qué quieres de mí? ¿Convertirme en el octavo invitado de otra de tus insípidas cenas?, ¿te enfurece tu incapacidad para llenar las sillas de tu espléndido comedor? Igualmente enfurecido, escribo:

¡Ay, Cati! Te cuento que estoy de maravilla. Mi trabajo es gratificante y me permite desarrollarme, no sólo profesional, sino personalmente. Mi jefe se ha convertido en uno de mis mejores amigos y, iquién diría!, su adorable secretaria puede entablar conversaciones fascinantes sobre la legislación que emite nuestro Honorable Congreso. Veo que sigues con Juan Antonio: dile que le envío un cordial saludo, y otro para ti, querida mía.

Delete

Delete all? ¡Que sí, delete all!

Ya pasan de las ocho y no ha llegado mi mejor amigo, claro que sólo es culpa suya por maximizar la venta de nuestros sedanes multicolores. Salut! Salut! Salut!, recuerdo cuando lo decías con toda la calidez y toda la sonrisa niña de nuestros primeros días. Te recuerdo también enfurecida porque, decías, era un inepto que no sentía la belleza del mundo; lo que jamás supiste fue cómo y cuánto sentía yo tu belleza, cómo disfrutaba de nuestra complicidad y de ti... claro, hasta que un día Juan Antonio te invitó a cenar ostras, que es lo único que comes desde entonces. ¿Por qué tomaste esa decisión? ¿Te habría molestado tanto pasar nuestros días en Avenida del Imán? Sé bien que no es cierto y que tampoco te hace falta el dinero que ahora tienes y que no sabes gastar, porque ni te gusta el vino ni lo sabes en tomar, así estés en Polanco o en Bordeaux... ¡Me lleva! ¡El Rojo Burdeos de la presentación! Debo terminarla antes de que llegue... sí, sí, debo terminarla, son ya las ocho y cuarto $\mathrm{y}$, en cualquier momento... 
¡Al fin regresamos del paseo alcohólico de mi marido! Picnic y vino francés, ¡se hace pasar por sibarita cuando, y lo descubrí desde que estábamos en Polanco, no es más que un cerdo escurriéndose taninos por el esófago! Taninos y días, Humberto, ¿será que otra vez se te ha escurrido el día? Es ya la tarde y no hay respuesta. Quién sabe, tal vez se conecte mientras actualizo las fotos del viaje.

\section{$11: 35: 13$}

... Mejor no, dijo mi jefe, el rojo no vende. Los estudios de mercado muestran una clara preferencia de los consumidores por el plateado. El rojo es un color muy agresivo, muy sexual, y parece que los clasemedieros al fin dictaron sentencia de muerte a su remedo de libido. Plata esmeril, Plata frígida... ¿Carmela está online?, me apresuro a desconectarme antes de que...

-¡Hola, Humberto! ¿Estás ahí?

¡Qué mujer! ¿Dónde quería que estuviera?

-Hola, Carmela. Sí, aquí estoy. ¿Cómo has estado?

-Muy bien, gracias, ¡qué alegría encontrarte por aquí! ¡Qué alegría y qué coincidencia! Juan Antonio y yo queríamos invitarte a cenar. Fíjate que ahorita no estamos en México, pero la próxima semana celebraremos nuestro viaje y nuestro regreso.

-Los felicito por el viaje, pero te adelanto que la próxima semana estaré muy ocupado y me será imposible verlos. Aún así, agradezco tu invitación y le mando muchos saludos a Juan.

-¡Gracias! Mira que la hemos pasado muy bien por acá. Es más, deberías darte una vuelta por el Mediterráneo. No te avergüences, querido: a todos los capitalinos les hace falta un buen baño de sol o, al menos, unas mimosas en el desayuno. Y es que: ¿para qué trabajar tanto si no vas a disfrutar tu salario? No vives para trabajar. Piensa que cuando uno se regala vacaciones, regresan los años y, ¿por qué no?, la juventud. Juan Antonio y yo todavía estamos sanos, fuertes y felices. 
¡Me lleva! ¡Baños de sol, mimosas en el desayuno, toda esa juventud empaquetada por los petulantes cruzados de la joie de vivre, que además se creen con el derecho de intervenir en el miserable "estilo de vida" de los otros! Lo único cierto es que entre la verdadera juventud y nosotros hay demasiados días como para que yo me compre semejante epifanía edulcorada. Amablemente rechazo la oferta de Carmela mientras escribo, al inicio de la presentación, en frígidas y monumentales letras plateadas:

Sedán. Tu actitud jovial se contagia. 